\title{
S.O.S Plasticidade: a clínica psicanalítica em movimento entre o presencial/remoto nas fronteiras da subjetividade em risco 82
}

\section{Mariângela Mendes de Almeida 83}

$\mathrm{Na}$ clínica dos estados primitivos da mente, com a qual estamos em contato clínico e investigativo a partir da experiência com nossa própria análise pessoal, com a prática junto a nossos pacientes de amplo espectro, incluindo funcionamentos autísticos (Mendes de Almeida, 2019, Mendes de Almeida et al, 2017) e com o aprofundamento em pesquisa psicanalítica, estamos já, desde a raiz, às voltas com desafios no continuum entre integrações e não integrações, ameaças à existência psíquica, necessidade de constituir continência a estados ainda não representados e tolerância ao sofrimento psíquico.

A plasticidade, portanto, como estado de mente (Mendes de Almeida, 2011) já está convocada e presente como instrumento do analista e como campo a se fertilizar pelo exercício do trabalho do vínculo, reverberando na construção dos aspectos de plasticidade, e ingredientes para a constituição de subjetividade e incipiente resiliência desenvolvidos pelo paciente. Tal atribuição e atitude psíquica vem ainda a ser mais intensamente requisitada a comparecer no contexto da pandemia global de 2020, viralizada em nosso cotidiano íntimo, familiar, social e político. Os movimentos da clínica psicanalítica em sua plasticidade possível e elasticidade técnica serão aqui considerados, levando-se em conta a necessidade de experimentar e refletir sobre novas modalidades de atendimento além da presencial física, que se impõem com as necessidades de afastamento social emergentes.

Ao longo deste trânsito do presencial físico ao presencial online, como presença sempre viva do analista (Quinet, 2020), experimentamos a convocação para uma disponibilidade de vínculo em que se enfatiza a relevância de diferentes tipos de comunicação, verbal e não verbal, recortados pelo enquadre escolhido (consciente e inconscientemente) pelo paciente ou pela família, no caso de nossos bebês e pequenas crianças.

\footnotetext{
82 Apresentado em Trabalhos livres no II Simpósio Bienal SBPSP "Fronteiras da Psicanálise: a clínica em movimento" no dia 21 de agosto de 2020.

83 Membro filiado ao Instituto da SBPSP, mestre pela Tavistock Clinic/UEL e doutora pela UNIFESP, coordenadora do Núcleo de Atendimento a Pais e Bebês - Pediatria/UNIFESP.
} 
Que mudanças ou permanências se operam através destes dispositivos atuais, que, conforme se manifesta Roussillon ( 2012) não indicariam o campo de uma psicanálise aplicada (que ele não crê existir), mas sim de uma psicanálise “encarnada” em seu próprio meio maleável, metaforizando e "de dentro" das características do próprio dispositivo a possibilidade do encontro psicanalítico, tendo como elemento atrator a transferência e valorizando a associatividade e a função simbolizante?

Sentimo-nos convidados para um espaço íntimo, inclusive com possibilidade de "adentramento" visual/geográfico, vivenciando assim várias gradiências de comunicação emocional possível, da fusão indiferenciada à invasividade a ser evitada. As várias nuances de "bilhetes de entrada", com ou sem câmera, com iniciativa de quem, sujeitos a que intempéries, interrupções ou desconexões, com que qualidade, vão inevitavelmente se configurando também junto ao que nos é comunicado pelo discurso falado e expresso corporalmente/facialmente/sonoramente em nuances de modalidade de voz e ritmos em turnos pressentidos, como comunicações a partir do imã atrator e configurativo do campo transferencial, evocando nossa associatividade (Roussillon 2009, 2012) e nossos movimentos em rêverie sonhante. (Bion, 1962).

Para alguém tão estrangeiro nesta prática tecnológica, surpreendi-me com o tanto de busca de fios de contato "por todos os poros", de disponibilidade e conexão emocional por vários canais sensoriais, por um lado um bombardeio, mas quem sabe, também uma experiência próxima do que seria a construção do processo denominado por Daniel Stern (1992) de percepção amodal, multimodal ou transmodal. Neste processo, muito característico do início comum no desenvolvimento dos bebês, vários canais sensoriais se integram para reconhecimento, generalização, abstração e atribuição de sentido a uma nova experiência. No caso dos bebês e crianças em risco ou com funcionamento autístico, a integração na consensualidade não ocorre com a mesma facilidade, dando lugar à preponderância de canais isolados de recepção e contato sensorial.

Como hipótese, poderíamos pensar que diante de uma nova linguagem e necessidade, desafiando nossos aspectos autocentrados, tendências à uniformidade e manutenção de nossas rotinas e zonas de conforto, seríamos ao mesmo tempo, provocados pela diferença da suposta "bidimensionalidade" ( 
Meltzer, 1979) da tela, procurando transcendê-la, incluindo possibilidades de encorpar qualquer possibilidade de dimensionalizar o vínculo? Estaríamos assim, desenvolvendo também uma certa "transmodalidade", fazendo uso da maior possibilidade que temos à mão e à mente, para fazer jus à nossa predisposição de busca de objetos humanos, de vínculos e relações, abrindo novas trilhas, continuando a esculpir o cérebro com nossas emoções, (Cunha, 2002) interferindo na arquitetura e nos movimentos de conectividade das redes neurais? (Laurentino, 2020).

Estaria aí, nesta busca tentando transcender a "suposta" restrição dimensional em primeiro tempo, um aspecto relacionado ao estado de uma certa sobrecarga e esgotamento em que nos vemos mergulhados, ao termos migrado para esta forma majoritária de conexão profissional e social? Estaríamos também transferindo para esta forma de contato toda uma bagagem constitutiva de vínculos e memórias sentidas e constituídas em outras modalidades?

Poderíamos pensar também em uma "transdimensionalidade, quando a "suposta" bidimensionalidade das telas sem volume vai sendo preenchida em seu espaço interno virtual entre nós e nossos pacientes por narrativas internas e compartilhadas, pela presença viva de um repertório em constituição como "corpo- envoltório" do vínculo?

Aproximações e distanciamentos vão também se constituindo e se instalando de forma peculiar, viva também, como na situação de um bebê de 1 ano com risco autístico que inicialmente não responde e não convoca os pais presentes ou a analista na tela, depois passa a, ao olhar da analista, aceitar a convocação dos pais, mas ainda aparentemente quer pegar o celular como objeto excitatório sensorial, para ligá-lo, ou se aproxima da tela pelo brilho, em olhar mesmerizado. Com a continuidade do trabalho mediado pelos pais, o bebê diversifica essa interação presencial, aceitando mais continuidade e buscando contato, por exemplo com brincadeiras de comidinha e frutas, que, ainda muito sério e em tom de um "aprendizado adquirido" oferece ou aceita, enquanto se irrita quando não consegue morder a fruta que a analista em diálogo lúdico, pareado em espelhamento (Laznik, 2020) lhe mostra. De maneira curiosa, isso ocorre concomitantemente em momento de intensa exploração oral, em que dentes nascendo estão lhe incomodando bastante. Quando esse incômodo se arrefece, após um período de contínuas sessões, e a presença de meu rosto na 
tela parece se fazer mais reconhecida, agora ao olhar da mãe narradora em voz e prosódia mais naturalmente modulada (nem superexcitada, nem pedagógica, nem desapontada, nem encobridora de desapontamento), surge leve sorriso de satisfação do bebê com o meu brincar de comer a fruta, que ele parece agora poder "incorporar" com maior diferenciação, em uma proto-diversão com a cena, sem irritação ou intolerância com a barreira da separabilidade.

Vemos aqui como é essencial a participação da família na instalação ou reinstalação da cena clínica, considerando que a plasticidade cerebral, se por um lado está sempre presente, por outro conta com um período sensível para ser mais fortalecida, amplificada e aproveitada ao máximo. Deparamo-nos aqui com uma polêmica desafiadora e delicada que demanda singularidade no olhar e no manejo psicanalítico. A questão da superexposição à tela tem sido, mesmo antes da COVID 19, uma preocupação pediátrica e alvo de cuidados no trato com as famílias, sendo inclusive apontada por alguns como um fator compensatório da mudança na qualidade do contato parental contemporâneo, relacionado à ênfase nas modalidades de descarga sensorial e busca de soluções automáticas em detrimento do processamento e mediações humanas, mais imprevisíveis e trabalhosas. Entretanto, para evitar esse paradoxo, propor um início ou continuidade de trabalho direto somente quando a pandemia acabar (algo também bastante imprevisível), pode acarretar consequências significativas de não abertura de brechas para a criança e para a família no acolhimento ao sofrimento psíquico na primeira infância (Crespin, 2004). Sabemos que o desenvolvimento de possíveis tendências à cristalização de traços de fechamento podem fortalecer circuitos de repetição sem contar com a ampliação de vias alternativas. (Mendes de Almeida et al, 2017)

Em tempos de pandemia, tais situações de tão pouco retorno emocional e dolorosas dificuldades mútuas de sintonia afetiva, ás vezes sem autorização interna para serem reconhecidas ou sem espaço para serem endereçadas e operacionalizadas (Muratori e Maestro,2007), somam-se a turbulências na rotina familiar, sobrecargas domésticas e profissionais, perdas dos eixos de organização das demandas familiares, contribuindo para o desinvestimento nos vínculos e busca de soluções prescritivas em detrimento dos enlaces intersubjetivos. Como profissionais também somos desafiados em várias vias, 
quando nosso próprio senso de continuidade e integração é posto à prova pela inesperada ruptura do enquadre habitual.

As redes de compartilhamento profissional e a discussão entre colegas de diversos campos do saber implicado com essa clínica em diversidade profissional (Silva e Mendes de Almeida, 2019; Laznik. M.C., 2020; Laurentino, 2020) também nos sustentam de forma significativa nestas novas investigações e intercâmbios durante os percursos exploratórios.

Curiosamente o conceito de modalidade de atendimento "remoto" como tem sido utilizado o termo "online" em nosso meio e idioma, alude ao sentido de distanciado, não só no espaço mas também no tempo, algo que se encontra longe no tempo, antigo, que aconteceu há muito tempo, ou atualmente, em nosso presente antecipador de um futuro precoce (pelo menos como tão global!), que se realiza através da conexão por mecanismos tecnológicos.

Parecemos estar aqui diante de uma transversalidade do tempo (passado, presente e futuro), e do espaço (interno, externo e transdimensional) que favorece a psicanálise como campo do conhecimento que desde seu surgimento a partir de Freud, se ocupa destas complexidades, em suas continuidades e rupturas. Talvez não seja à toa que nossa profissão possa permanecer tão ativa durante a pandemia, mais viva do que nunca em nossos trânsitos virtuais com pacientes e trocas interprofissionais: é nossa mente que trabalha, psicanaliticamente, em qualquer lugar, sustentada por nosso setting interno, e são também nossas mentes que sofrem e demandam, individualmente ou como grupo sócio-político, nossa compreensão e sentido para o momento em que vivemos...

\section{Referências}

Bion, W. (1962) Learning from experience. London: Heinemann.

Crespin, G.C. (2004). A clínica precoce: o nascimento do humano. São Paulo, SP: Casa do Psicólogo.

Cunha (2002). A revolução dos bebês. Psicanalítica. A revista da SPRJ. Volume II, número 1.

Laurentino, S. (2020) Curso: Neurociências e Psicanálise, organizado pela Fafire e Ciclos da Vida, Recife de abril a junho de 2020.

Laznik, M.C. (2020). Encontros do Grupo Rieppi Brasil (comunicações pessoais e promoção de intercâmbios intergrupais), desde março de 2020. 
Meltzer, D. (1979). La psicología de los estados autistas y de la mentalidad postautista. In D. Meltzer, J. Bremner, S. Hoxter, D. Weddell \& I. Wittenberg. Exploración del autismo: un estudio psicoanalítico (pp. 21 - 39). Buenos Aires. Paidós.

Mendes de Almeida, M. (2011). Facilitando trânsitos no espaço analítico: o brincar como estado de mente.

Jornal de Psicanálise - Sociedade Brasileira de Psicanálise de São Paulo - Vol. 44, junho 2011, n.80, São PAULO: SBPSP.

Mendes de Almeida, M; Zimmerman, V.: Brito, T.; Meirelles, S.; Cangueiro, L., Possato, L. Mori, J.; Vieira, S; Oliveira, M.V. (2017). Vias alternativas para o desenvolvimento no atendimento psicanalítico a crianças pequenas em risco psíquico: o corpo em cena. In Erika Parlato e D. Cohen (Orgs.), O bebê e o outro. (pp. 141-154). São Paulo, S.P: Instituto Langage

Mendes de Almeida, M. (2019). Sobre brilho nos olhos e mudança psíquica: evocações a partir da clínica psicanalítica dos transtornos de espectro do autismo. In Silva, M.C.P., Mendes de Almeida, M. (2109) Infância, vínculos e diversidade. profissional - Espaços para Interlocução. (Pp 443 - 456). São Paulo: Blucher.

Muratori, F. \& Maestro, S. (2007). Early signs of autism in the first year of life. In S. Acquarone (Ed.), Signs of autism in infants: recognition and early intervention (pp.46-61). London, England: Karnac Books.

Quinet, A. (2020). Lives proferidas durante a pandemia do Covid 19.

Roussillon R. (2009). A associatividade e as linguagens não verbais. Revista de Psicanálise da SPPA, v. 16, n. 1, p. 143-165.

Roussillon, R. (2012). Manual da prática clínica em psicologia e psicopatologia. São Paulo: Blucher.

Silva, M.C.P., Mendes de Almeida, M. (2109) Infância, vínculos e diversidade profissional - Espaços para Interlocução. São Paulo: Blucher.

Stern, D. (1992). O mundo interpessoal do bebê: uma visão a partir da psicanálise e da psicologia do desenvolvimento. Porto Alegre, R.S.: Artes Médicas. 